\title{
Correction to: Working with Misspecified Regression Models
}

\author{
Richard Berk ${ }^{1,2}\left(\right.$ Lawrence Brown ${ }^{2} \cdot$ Andreas Buja $^{2} \cdot$ Edward George $^{2} \cdot$ Linda Zhao $^{2}$
}

Published online: 10 June 2020

๑) Springer Science+Business Media, LLC, part of Springer Nature 2020

\section{Correction to: J Quant Criminol (2018) 34:633-655 https://doi.org/10.1007/s10940-017-9348-7}

Unfortunately, the subjected Special Issue article has been inadvertently included in the regular issue volume 34, Issue 3, September 2018, of this journal. We apologize for the error.

Publisher's Note Springer Nature remains neutral with regard to jurisdictional claims in published maps and institutional affiliations.

The original article can be found online at https://doi.org/10.1007/s10940-017-9348-7.

Richard Berk

berkr@sas.upenn.edu

1 Department of Criminology, University of Pennsylvania, Philadelphia, USA

2 Department of Statistics, University of Pennsylvania, Philadelphia, USA 